\title{
EFFECT OF NON-ELECTROACTIVE ADDITIVES ON THE EARLY \\ STAGE PYRROLE ELECTROPOLYMERIZATION ON INDIUM TIN OXIDE ELECTRODES.
}

\section{A. Castro-Beltran ${ }^{1,2, \uparrow}$, C. Dominguez ${ }^{3}$, D. Bahena-Uribe ${ }^{3}$, S. Sepulveda-Guzman, , $^{*}$ and R. Cruz-Silva ${ }^{4}$}

${ }^{1}$ Facultad de Ingeniería Mecánica y Eléctrica. Universidad Autónoma de Nuevo León, Ave. Pedro de Alba s/n, Ciudad Universitaria, C.P.66451, San Nicolás de los Garza, N.L., México.

${ }^{2}$ Centro de Innovación Investigación y Desarrollo en Ingeniería y Tecnología (CIIDIT). Universidad Autónoma de Nuevo León, PIIT-Monterrey C.P. 66600 Apodaca, N.L., México

${ }^{3}$ Centro Investigación en Ingeniería y Ciencias Aplicadas (CIICAp), Universidad Autónoma del Estado de Morelos. Av. Universidad 1001, Col. Chamilpa C.P. 62209, Cuernavaca, Mor. México

${ }^{4}$ Research Center for Exotic NanoCarbon, Shinshu University, 4-17-1 Wakasato, Nagano 380-8553, Japan.

^ Current address: Facultad de Ingeniería Mochis, Universidad Autónoma de Sinaloa, Fuente de Poseidón y Ángel Flores s/n, Ciudad Universitaria, C.P. 81223, Los Mochis, Sinaloa, México.

*E-mail: selene.sepulvedagz@uanl.edu.mx; Tel: 52 (81) 8329-400; Fax: 52 (81) 1052-3321 
Abstract. The use of non-electroactive additives during electrodeposition of conducting polymers has long been used to modify the properties of deposited films. These additives can improve the adhesion, and not only change the morphology and deposition rate but also modify the chemical composition of the electrodeposited polymer. Several compounds have been used to modify deposition of polypyrrole; however, there is no systematic study of these compounds. In this work, we comparatively studied several water soluble chemical compounds, a cationic polymer, an anionic polymer, a cationic surfactant, and an anionic surfactant during potentiostatic electrodeposition of polypyrrole. In order to study the effect of these compounds on the interface, where the electrochemical polymerization takes place, we used Electrochemical Impedance Spectroscopy. The morphology during the initial stage of growth was studied by atomic force microscopy, whereas the resulting polypyrrole films were observed by scanning electron microscopy.

Keywords: Polypyrrole, Thin films, Atomic Force Microscopy

\section{Introduction}

Polypyrrole (PPy) is one of the most promising intrinsically conducting polymers. It combines good electrical conductivity, chemical stability and biocompatibility [1,2]. This polymer is usually obtained through oxidative polymerization of pyrrole. The oxidation can be carried out by many different routes, such as electrochemical [3], chemical [4] or biocatalytic [5] methods. The electrochemical polymerization was the first method developed [6] and remains as one of the most important due to its simplicity. Electropolymerized PPy films result in unique coatings with potential application in 
biomedical field and corrosion protection [7-9]. In spite of 30 years of research in electrochemical polymerization of pyrrole and pyrrole derivatives, there are still many issues that are under study. Many research works have been focused in the strong effect of reaction parameters such as solvent composition [10], electrolyte [11], potential or current density [12,13], concentration of monomer [14], composition of working electrode [15,16] on the electrochemical deposition and mechanical properties of PPy films. S. Carquigny et al. [17] studied the effect of electrolyte solvent on the morphology and the thickness of PPy films by using different electrolyte solutions of water and acetonitrile during electrochemical polymerization reaction. However, the electrolyte solution of the monomer can also be modified by adding a non-electroactive substance whose purpose is to modify the electrochemical deposition without being oxidized or polymerized at the electrode. Additives such as poly(vinylalcohol) have been used to improve PPy adhesion to steel [18], whereas surfactants such as cetyltrimethylammonium bromide (CTAB) [19,20], or dioctyl sodium sulfosuccinate (AOT) [21] and nonionic nonaphenol polyethyleneoxy ether [22] have been widely employed to induce the growth of nanostructures, increase the capacitance, and also improve the adhesion or mechanical properties. In a different approach, the electrochemical oxidation of pyrrole in a mixed electrolyte with sodium dodecylsulfonate and poly(ethylene glycol) and by using well-aligned $\mathrm{ZnO}$ nanowires arrays as templates resulted in a nanostructured thin film [23]. Strong acid polyelectrolytes, such as sulfonated polystyrene, have also been investigated as counterions during electrochemical deposition [24]. In addition, some other additives, such as 2,4dichlorophenoxy acetic, have been added during electrodeposition of PPy to induce electrochemical sensitivity by taking advantage of molecular recognition [25] in order to 
obtain a PPy electrode useful for chemical sensing. Whenever a non-electroactive compound is present at the electrode-electrolyte interface, the place where oxidation of pyrrole takes place, many characteristics of resulting film will change. It has well known that nucleation is a very important process for the film development during electrodeposition. Many attempts to indirectly study this process rely on the equations used for metal deposition, and it has been affirmed that PPy behaves similarly [26]. On the other hand, some authors claimed that under certain polymerization conditions, pyrrole electropolymerization strongly deviates from the Faraday law that explains metal electrodeposition due to the formation of oligomers [27]. Indeed, there is not a single regime for PPy growth. It has been found that the PPy film can grow in a 2-D lateral fashion, 3-D way, or a mixture of both [28]. Recently, a electropolymerization model that takes into account PPy diffusion limited multiple 3D nucleation and growth and pyrrole electro-oxidation on the growing surface of the PPy nuclei was published [29]. With the development of high resolution microscopy the nucleation process can now be followed by atomic force microscopy (AFM). G. Longo et al. [30] reported a strong influence of using an anionic biopolymer as additive on the morphology of the electrodeposited PPy films at early stage of growth by AFM. We believe the best approach to study early stage electropolymerization is to combine an array of techniques, such as high resolution microscopic techniques and electrochemical measurements in order to study the PPy electropolymerization process.

In this work, we studied the early stage and the further growth of PPy film using different types of non electroactive ionic-additives. We studied a cationic and anionic surfactant, CTAB and AOT respectively, and a cationic and anionic polyelectrolytes, poly (4- styrene sulfonic acid-co-maleic acid) sodium salt (PSSMA) and poly (diallyldimethylammonium 
chloride) (PDADMAC), respectively. The PPy film deposition is strongly affected by the type of additive. In addition, the growth mechanism of PPy film was studied by analyzing the PPy nucleation and film growth using AFM and scanning electron microscopy (SEM) respectively. This study also includes the effect of ionic additive on adhesion properties and impedance of electrodeposited PPy films.

\section{Experimental part}

\subsection{Materials}

Pyrrole, AOT, PSSMA, PDADMAC and CTAB were of reagent grade and purchased from Sigma Aldrich. Hydrochloric acid was acquired from J.T. Baker.

\subsection{Preparation of the monomer/additive solution}

In a typical experiment the electrolyte solution for deposition of PPy films was prepared using 0.2 M pyrrole and 0.2 M hydrochloric acid in deionized water. The deposition of PPy films in presence of non-electroactive additives was carried out using the electrolyte solution with $1 \mathrm{wt} \%$ of respective additive (AOT, CTAB, PSSMA and PDADMAC).

\subsection{Electropolymerization of pyrrole}

Electrochemical deposition of pyrrole was carried out in a typical three-electrode cell using a Gill-AC potentiostat from ACM instruments. The reference electrode was a silver/silver chloride electrode whereas the counter electrode was a platinum wire electrode. Indium Tin 
oxide coated polyester sheet was purchased to Sigma Aldrich (Rs=60 $\Omega$ ). The PPy was potentiostatically electrodeposited at $800 \mathrm{mV}$ vs $\mathrm{Ag} / \mathrm{AgCl}$ for $1.5 \mathrm{~s}$ and $300 \mathrm{~s}$. The electrodes were coated with a plastic film to protect them from contamination. Before polymerization, the plastic film was removed and the electrode quickly immersed in the electrolyte solution. The deposition was started immediately to avoid electrode dissolution in the acidic media. Cyclic voltammetry experiments were carried out in a BAS Epsilon potentiostat with an aqueous electrolyte solution of $0.2 \mathrm{M}$ hydrochloric acid, $0.2 \mathrm{M}$ pyrrole and $1 \mathrm{wt} \%$ of additive in a potential range from $-300 \mathrm{mV}$ to $800 \mathrm{mV}$ at a scan rate of 50 $\mathrm{mVs}^{-1}$.

\subsection{Characterization}

A Gill-AC Potentiostat from ACM instruments was used for potentiostatic electrochemical deposition and electrochemical impedance spectroscopy (EIS) studies. EIS of the films were studied in a monomer free $0.2 \mathrm{M}$ hydrochloric acid solution, working with a frequency range from $0.1 \mathrm{~Hz}$ to $100 \mathrm{kHz}$, at open circuit potential using a sinusoidal wave of $10 \mathrm{mV}$ amplitude. The electrodes surface was studied by AFM in tapping mode using Nanoscope IV equipment from Veeco. Phase and topography images were simultaneously acquired. PPy films deposited on the indium tin oxide (ITO) electrodes were observed by scanning electron microscopy using a Nova NanoSEM 200 from FEI. The samples were analyzed as prepared without any conductive coating at an accelerating voltage of $15 \mathrm{kV}$ and a working distance of $5 \mathrm{~mm}$ using the Helix detector. Fourier transform infrared spectroscopy (FTIR) spectra were acquired in Nicolet 6700 spectrophotometer in a transmission mode with experimental parameters of 32 scans and $4 \mathrm{~cm}^{-1}$ of resolution in a 
wavelength range from 4,000 to $400 \mathrm{~cm}^{-1}$ using $\mathrm{KBr}$ pellets. The adhesion was studied by submitting the films to a peel test using $3 \mathrm{M}$ adhesive tape.

\section{Results}

\subsection{PPy electrodeposition}

During electrodepositon of PPy current density vs time measurements indicate the rate of oxidation of the monomer at the electrode. Figure 1 shows the chronoamperometric (CA) curves of polpyrrole electrodeposition in presence of different additives over ITO coated PET films electrodes. The current indicates that the deposition can be divided mainly in two stages. The first one lasts a few seconds and a characteristic increase in current indicates the oxidation of the pyrrole monomer at the electrode interface and a primarily growth of the nuclei [31]. During the second stage, the value of current usually raises to a maximum due to the spread and collapse of PPy nuclei, which is indicative of polymer film growth followed by either stabilization or a decrease of current intensity. PPy control film and the sample synthesized in presence of CTAB show a delay in the current before starts to increase. This indicates that the monomer is more prone to be oxidized after a certain amount of polymer has been deposited on the electrode in an autocatalytic way. Consequently, when the electrode is clean, the oxidation rate is very low, but after a few seconds when some polymer has been deposited, the current increases because the monomer is oxidized at higher rate. On the other hand, PDADMAC, AOT, and PSSMA induced the fast oxidation of the monomer at the ITO electrode; however, only the anionic molecules, AOT and PSSMA showed current densities clearly above the current density 
obtained in the control reaction. This high current indicates that these molecules are promoting a fast oxidation rate of the monomer which should result in faster growth of the film. By integration of the current density we can obtain the charge density, which is proportional to the amount of oxidized monomer, according to Faraday's law. Table 1 summarizes the charge density after $300 \mathrm{~s}$ of electrodeposition. It can be seen that as compared to our PPy control sample $\left(255.0 \mathrm{mC} / \mathrm{cm}^{2}\right)$, the anionic AOT and PSSMA showed increased efficiency, whereas the cationic additives PDADMAC and CTAB showed lower charge densities, suggesting that these molecules slightly slows down the pyrrole oxidation. This was further corroborated by obtaining the pyrrole oxidation potential during cyclic voltammetry experiments in presence of additives. Table 1 also shows that pyrrole oxidation potential shifts to lower values for anionic additives such as AOT and PSSMA. The improvement effect is possibly due to that during the anodic oxidation of pyrrole the formation of positively charged PPy backbone occurs, which is stabilized by the anionic additive that act as counter-ions instead of $\mathrm{Cl}^{-}$ions. Also, this favored the absorption of oxidized pyrrole molecules on to the ITO electrode increasing the CA current values. The CA current value is considerably higher in presence of PSSMA, which is possible due to the number of anionic groups available to counterbalance positive PPy chain PSSMA per mol is higher than those in AOT. In addition, it is possible that, adsorption of AOT on ITO electrode was hindered because AOT can easily form micelles in solution. On the other hand, it is possible that before deposition the cationic additive gets adsorbed on ITO electrode and during electrodeposition, a competition between positively PPy backbone and the positively charged surface due to the CTAB and PDADMAC, occurs avoiding Pyrrole deposition on ITO electrodes. This is clearly observed by induction period 
and the low current values in CA curves of PPy in presence of cationic additives even lower values than those observed in CA curves of additive-free PPy films.

\subsection{Nuclei growth}

A key process during PPy electrodeposition is the formation of polymer nuclei over the bare electrode $[32,33]$. We used AFM to analyze the film deposited after 1.5 seconds at 800 $\mathrm{mV}$ (vs $\mathrm{Ag} / \mathrm{AgCl}$ ). Figure 2 shows the AFM height and phase image of PPy films. The shape of those nuclei is mounting like with a diameter of about $50 \mathrm{~nm}$ maximum. The RMS roughness of a $1 \mu^{2}$ in the sample increases from $1.43 \mathrm{~nm}$ for the bare ITO electrode to $1.63 \mathrm{~nm}$ after the PPy deposition. The polydispersity in diameter of the polymer globules nuclei suggests that a progressive nucleation took place on the electrode. In addition, theoretical models of progressive/instantaneous nucleation in three dimensional (3D) and two dimensional (2D) direction were compared with the experimental data by taking the coordinates of the current maximum $I_{\max }$ and $t_{\max }$ from the chronoamperometric curves. The following equations were used to create the plots [24]: 2-D progressive $I / I_{\max }=\left(t / t_{\max }\right)^{2} \exp \{-$ $\left.2 / 3\left(t^{3}-t^{3}{ }_{\max }\right) / t^{3}{ }_{\max }\right\}, 2-\mathrm{D}$ instantaneous $I / I_{\max }=\left(t / t_{\max }\right) \exp \left\{-1 / 2\left(t^{2}-t^{2}\right.\right.$ max $\left.) / t^{2}{ }_{\max }\right\}, 3-\mathrm{D}$ progressive $\left(I / I_{\max }\right)^{2}=1.2254\left(t / t_{\max }\right)\left\{1-\exp \left[-2.3367\left(t / t_{\max }\right)^{2}\right]\right\}^{2} \quad$ and $\quad 3-\mathrm{D} \quad$ instantaneous $\left(I / I_{\max }\right)^{2}=1.9542\left(t / t_{\max }\right)\left\{1-\exp \left[-1.2564\left(t / t_{\max }\right)\right]\right\}^{2}$. The results show that experimental data match with the 3D progressive theoretical plot (Figure 3b). This result is supported by the AFM image, where a wide distribution of nuclei size, ranging from $15 \mathrm{~nm}$ to $40 \mathrm{~nm}$, can be seen. Figure 4 shows the AFM images of PPy films growth in the presence of a CTAB and AOT, a cationic and anionic surfactant, respectively. It can be seen that when CTAB was 
added, there was a significantly lower amount of polymer deposited, and the polymer clusters are of smaller size, with maximum diameter of about $40 \mathrm{~nm}$ in diameter. (Figure $4 \mathrm{a}$ and $4 \mathrm{~b})$. This is in agreement with the low current density observed in the respective chronoamperometric curve (Figure 1, PPy-CTAB). On the other hand, when AOT was added into electrolyte solution, the amount of PPy deposits increased and the nuclei exhibited a globule-like shape with $200 \mathrm{~nm}$ of diameter (Figure 4c and 4d). This is accompanied by a dramatic increase in the current density during the early seconds in the chronoamperometric curve (Figure 1, PPy-AOT). In addition, when these globules increase their size and reach each other, they do not fuse together; instead keep growing in perpendicular direction to the electrode. Even though the polydispersity in clusters size in both samples indicates still a progressive nucleation, it is clearly seen that adding surfactants to the electrolyte shift the nucleation to a preferentially instantaneous process. This is supported by comparing the experimental data with theoretical plots of progressive and instantaneous nucleation in 3D and 2D directions. The experimental data of PPy in presence of AOT films, exhibit better fitting with the theoretical model of 3D instantaneous (Figure 3d). In addition, the clusters during early stage PPy films deposition in presence of polyelectrolytes were also analyzed by AFM and the images are shown in Figure 5. The nuclei deposits of PPy exhibit a mount like morphology when cationic polyelectrolyte, PDADMAC, was added (Figure 5a and 5b). The nuclei morphology is similar to that observed in PPy deposits using cationic surfactant (CTAB) but a higher amount of polymer and smaller cluster size can be seen. Moreover, the PPy deposits obtained in presence of anionic polyelectrolyte, PSSMA, have a globule like morphology (Figure 5c and 5d) and it is very similar to the resulting morphology using the AOT except for the smaller size in globule diameter. 
Figure 6 shows the Bode diagram of the electrochemical set up before (filled circles) and after $1.5 \mathrm{~s}$ of polymerization (hollow circles) for the PPy (in black) and PPy in presence of AOT samples (in red). In the high frequency part of the plot, the impedance of the sample before and after polymerization is similar and corresponds to the solution resistance. However, at low frequencies it can be seen that after $1.5 \mathrm{~s}$ of polymerization, both samples decrease its impedance due to deposition of conductive polymer on the electrode, increasing its surface area. However, the reduction in the sample with AOT is considerably higher than that shown for the sample without AOT, suggesting the formation of a more conductive interface resulting in a thicker film.

\subsection{Morphology of the film by SEM}

PPy films morphology was examined after 300 seconds of deposition by SEM. Figure 7 shows the final morphology of the films deposited using the different additives. The PPy film prepared without additives shows the typical "wrinkled sheet" morphology and the PPy film prepared in presence of CTAB showed a similar morphology which is more close to a film than to particles fused together. On the other hand, PPy film prepared using AOT as additive shows a morphology resulting from the individual growth of globules that reached a size of ca. $3.0 \mu \mathrm{m}$ in diameter and they are not completely fused to each other. A similar morphology is also observed when PPy film was deposited in presence of either anionic or cationic polyelectrolyte. However, globules of small size about $500 \mathrm{~nm}$ were observed in deposited PPy film in presence of anionic polyelectrolyte, PSSMA, resulting in a dense continuous film. Whereas when cationic polyelectrolyte, PDADMAC, was added 
as additive during deposit of PPy films the globules grown and fused to each other to form a film with mountain-like aggregates. By comparing with the SEM with the AFM electropolymerization early-stage, it is suggested that the PPy film growth processes takes place on the previously deposited aggregates (overgrowth) which were observed by AFM. Nevertheless, in presence of certain additives such as CTAB a transition to film and 2D growth was clear whereas the rest of the samples have a 2D growth but maintains an overall globule like morphology. In addition, the thickness films were measured directly from the cross-section SEM images of the films and the results are shown in Table 1. The results show that thin films of PPy with thickness between $400 \mathrm{~nm}$ - $500 \mathrm{~nm}$ were obtained when cationic additive is added to the electrolyte. Whereas, PPy films with thickness larger than $900 \mathrm{~nm}$ can be obtained by adding anionic additive into the electrolyte. The results agree with chronoamperometric curves, with the values obtained for charge density and also, with the observations made by AFM analysis, where anionic additives promote a high amount of PPy deposits increasing the current density and the film thickness.

\subsection{Fourier transform infrared spectroscopy}

PPy films were studied by FTIR to detect the presence of the additives. Figure 8 shows the spectrum of the PPy film. The main peaks at $1,633 \mathrm{~cm}^{-1}, 2,925 \mathrm{~cm}^{-1}$, and $3,422 \mathrm{~cm}^{-1}$ have been assigned to the $\mathrm{C}=\mathrm{C}, \mathrm{C}-\mathrm{H}$ y $\mathrm{N}-\mathrm{H}$ stretching vibrations respectively [34]. The absorption bands at $1,548 \mathrm{~cm}^{-1}$ and $1,448 \mathrm{~cm}^{-1}$ have been assigned to the $\mathrm{C}-\mathrm{C}$ stretching of the pyrrole ring. The bands at $1,042 \mathrm{~cm}^{-1}$ and $907 \mathrm{~cm}^{-1}$ corresponds to the $\mathrm{C}=\mathrm{C}-\mathrm{H}$ in plane and out of plane bending vibrations. The peak at $1,170 \mathrm{~cm}^{-1}$ has been assigned to the $\mathrm{C}-\mathrm{N}$ stretching [35]. The spectrum corresponds well to previously reported PPy samples obtained by potentiostatic deposition [36]. Besides the characteristics bands of PPy (Figure 
8e) the FTIR spectrum for the PPy film deposited in presence of AOT (Figure 8a) display the three more bands at $1,730 \mathrm{~cm}^{-1}, 1,094 \mathrm{~cm}^{-1}$ and $1,420 \mathrm{~cm}^{-1}$ associated to the $\mathrm{C}=\mathrm{O}, \mathrm{C}-\mathrm{O}$ and $\mathrm{SO}_{3}{ }^{-}$stretching vibrations of AOT [37]. Whereas an additional band at $1,464 \mathrm{~cm}^{-1}$ associated with the bending vibration of $-\mathrm{CH}_{2}$ was observed in the PPy film spectrum deposited in presence of CTAB (Figure 8b) [38]. In addition, the characteristics bands of PSSMA and PDADMAC were also observed in the respective PPy film. The bands at $1,711 \mathrm{~cm}^{-1}$ and $1,183 \mathrm{~cm}^{-1}$ associated to the $\mathrm{C}=\mathrm{O}$ and $\mathrm{SO}_{3}{ }^{-}$stretching vibrations respectively of PSSMA (Figure 8d) were observed in the FTIR spectrum [39]. More over the assigned bands of stretching vibrations of $-\mathrm{NH}_{3}{ }^{+}$and $\mathrm{C}\left(\mathrm{CH}_{3}\right)_{2}{ }^{+}$in PDADMAC (Figure 8c) were

observed at $1,640 \mathrm{~cm}^{-1}$ and $1,464 \mathrm{~cm}^{-1}$ respectively [40]. FTIR analysis indicates that a small amount of the additives were adsorbed in the PPy film during synthesis. Whereas the polymeric additives might be adsorbed by entanglement, the low molecular weight surfactants might be adsorbed by cationic or anionic species at the interface. The entanglement adsorption of polymer chains can be described as a restriction of molecular motion by other chains. Figure 9 shows a graphical description of both adsorption mechanisms by polymeric additives (entanglement) and surfactant additives (adsorption). This mechanism is more likely for anionic additives due to the electrostatic interaction with the cationic PPy backbone and it is clearly observed in the resulting morphology of the films. Wrinkled sheet morphology resulted in the PPy-PSSMA film whereas, a film composed by particles fused together is observed in the PPy-AOT film.

\subsection{Adhesion test}

One of the main drawbacks of PPy films is their poor adhesion to the electrode. One way to overcome this problem is by using additives that promote the adhesion of PPy films to the 
electrode during deposition [15]. We test the effect of these additives by using the standard scotch tape test (Figure 10). The PPy film (Figure 10a) was completely detached from the electrode after the tape was removed; this shows the poor interaction between the PPy film and ITO electrode. Similarly, PPy-CTAB and PPy-AOT films (Figure 10b and Figure 10c, respectively) showed low adhesion, and only the edges remained attached to the substrate whereas most of the electrode surface appeared clean after the test. On the other hand, PPy films prepared in presence of PDADMAC (Figure 10d) showed a considerably increase of the adhesion, and approximately $50 \%$ of the surface of the electrode showed coverage by PPy after the test. The anionic polymer, PSMMA (Figure 10e) showed only a slight improvement, and even though most of the sample was detached, small particles of polymer remained attached to the electrode. The adhesion properties are strongly influenced by the adsorption of PPy/additives on ITO electrode. In the PPy-AOT film, PPy particles are fused together but without forming a dense and continuous film decreasing the adhesion properties. However, for the PPy films deposited in presence of polymeric additives, the adhesion properties clearly increased possibly due to the entanglement adsorption. Nevertheless, for the PPy-PDADMAC film the adhesion was noticeably improved possibly due to the polymeric additive adsorbed on the ITO electrode during the early stage of electrodeposition acting as adhesion promoter.

\section{Conclusions}

Chronoamperometry, AFM and FE-SEM analyses show that anionic additives, such as AOT, promote the oxidation of the monomer on the electrode and $3 \mathrm{D}$ instantaneous nuclei growth. The theoretical modeling confirms that growth mechanism changed from 3D progressive for the PPy without additives to 3D instantaneous when anionic additives were 
added. AFM were used to visualize the early stage of PPy deposits on the surface. We were able to detect the decrease in impedance due to formation of a thin layer of conductive polymer in the initial stages of polymerization. Anionic additives promote the oxidation of the monomer and consequently increase the polymerization rate, whereas polymeric additives promote the adhesion of the electrodeposited PPy film.

\section{Acknowledgements}

R. Cruz-Silva acknowledges the support from the Exotic Nanocarbon Project, Japan Regional Innovation Strategy Program by the Excellence, JST. C. Dominguez acknowledges S. Serna for his technical assistance.

\section{References}

[1] A.G. MacDiarmid, Polyaniline and polypyrrole: Where are we headed?, Synthetic. Met. 84 (1997) 27-34.

[2] P.M. George, A.W. Lyckman, D.A. LaVan, A. Hegde, Y. Leung, R. Avasare, C. Testa, P.M. Alexander, R. Langer, M. Sur, Fabrication and biocompatibility of polypyrrole implants suitable for neural prosthetics, Biomaterials. 26 (2005) 3511-3519.

[3] S. Sadki, P. Schottland, N. Brodie, G. Sabouraud, The mechanisms of pyrrole electropolymerization, Chem. Soc. Rev. 29 (2000) 283-293.

[4] M. Omastová, M. Trchová, J. Kovárová, J. Stejskal, Synthesis and structural study of polypyrroles prepared in the presence of surfactants, Synthetic Met. 138 (2003) 447-455.

[5] R. Cruz-Silva, E. Amaro, A. Escamilla, M.E. Nicho, S. Sepulveda-Guzman, L. Arizmendi, J. Romero-Garcia, F.F. Castillon-Barraza, M.H. Farias, Biocatalytic synthesis of polypyrrole powder, colloids, and films using horseradish peroxidase, J. Colloid. Interf. Sci. 328 (2008) 263-269.

[6] A.F. Diaz, K.K. Kanazawa, G.P. Gardini, Electrochemical polymerization of pyrrole J. Chem. Soc., Chem. Commun. (1979) 635-336.

[7] H. Xu, J.M. Holzwarth, Y. Yan, P. Xu, H. Zheng, Y. Yin, S. Li, P. X. Ma. Conductive PPY/PDLLA conduit for peripheral nerve regeneration. Biomaterials 35 (2014) 225-235. 
[8] J. Ren, F. Heb, L. Zhang The construction and application of a new PPY-MSPQC for 1asparaginase activity assay. Sensors and Actuat. B 145 (2010) 272-277.

[9] J. Liao, Y. Zhang, G. Tan, C. Ning, Nanostructured PPy coating on titanium fabricated via template-free electrochemical polymerization in PBS. Surf. Coat. Tech. 228 (2013) S41-S43.

[10] S. Lee, H. Sung, S. Han, W. Paik, olypyrrole film formation by solution-surface electropolymerization: influence of solvents and doped anions, J. Phys. Chem. 98 (1994) $1250-1252$.

[11] C.A. Ferreira, S. Aeiyach, M. Delamar, P.C. Lacaze, Electropolymerization of pyrrole on iron electrodes: Influence of solvent and electrolyte on the nature of the deposits, J. Electroanal. Chem. Interfacial Electrochem. 284 (1990) 351-369.

[12] D.A. Kaplin, S. Qutubuddin, Electrochemically synthesized polypyrrole films: effects of polymerization potential and electrolyte type. Polymer 36 (1995) 1275-1286.

[13] M.A. Raso, M.J. González-Tejera, I. Carrillo, E. Sanchez de la Blanca, M.V. García, M.I. Redondo, Electrochemical nucleation and growth of poly-N-Methylpyrrole on copper, Thin Solid Films 519 (2011) 2387-2392.

[14] H.M. Alfaro-López, J.R. Aguilar-Hernandez, A. Garcia-Borquez, M.A. HernandezPerez and G.S. Contreras-Puente, Electropolymerization of Polypyrrole Films in Aqueous Solution with Side-Coupler Agent to Hydrophobic Groups. Interface Controlled Organic Thin Films 129 (2009) 73-78.

[15] M. Sharifirad, A. Omrani, A. A. Rostami, M. Khoshroo, Electrodeposition and chracterization of polypyrrole films on copper, J. Electroanal. Chem. 645 (2010) 149-158.

[16] Y. Wang, D.O. Northwood, An investigation into the nucleation and growth of an electropolymerized polypyrrole coating on a 316L stainless steel surfasse, Thin Solid Films 516 (2008) 7427-7432.

[17] S. Carquigny, O. Segut, B. Lakard, F. Lallemand, P. Fievet, Effect of electrolyte solvent on the morphology of polypyrrole films: Application to the use of polypyrrole in pH sensors, Synthetic Met. 158 (2008) 453-461.

[18] J.G. Gonzalez-Rodriguez, M.A. Lucio-García, M.E. Nicho, R. Cruz-Silva, M. Casales, E. Valenzuela, Improvement on the corrosion protection of conductive polymers in pemfc environmets by adhesives, J. Power Sources, 168 (2007) 184-190.

[19] W. Quan-Fu, H. Kuan-Xin, M. Hong-Yu, Z. Xiao-Gang, Electrochemical capacitance of polypyrrole nanowire prepared by using cetyltrimethylammonium bromide (CTAB) as soft template, Mater. Chem. Phys. 101 (2007) 367-371. 
[20] T. Dai, X. Yang, Y. Lu, Controlled growth of polypyrrole nanotubule/wire in the presence of a cationic surfactante, Nanotechnology. 17 (2006) 3028-3034.

[21] D.O. Flamini, S.B. Saidman, Characterization of polypyrrole films electrosynthesized onto titanium in the presence of sodium bis(2-ethylhexyl) sulfosuccinate (AOT). Electrochim. Acta 55 (2010) 3727-3733.

[22] Y. Li, J. Ouyang, Effect of nonionic surfactant additives on the electropolymerization of pyrrole in aqueous solutions. Synthetic. Met. 113 (2000) 23-28.

[23] M. Li, J. Yuan, G. Shi, Electrochemical fabrication of nanoporous polypyrrole thin films, Thin Solid Films 516 (2008) 3836-3840.

[24] E. Andreoli, D. A. Rooney, W. Redington, R. Gunning, C. B. Breslin, Electrochemical Deposition of Hierarchical Micro/Nanostructures of Copper Hydroxysulfates on Polypyrrole-Polystyrene Sulfonate Films. J. Phys. Chem. C 115 (2011) 8725-8734.

[25] C. Xie, S. Gao, Q. Guo, K Xu, Electrochemical sensor for 2,4-dichlorophenoxy acetic acid using molecularly imprinted polypyrrole membrane as recognition element, Microchim. Acta 169 (2010) 145-152.

[26] H. Bing-Joe, S. Raman, L. Yi-Liang, Evaluation of Structure, Nucleation and Growth Mechanism of Electropolymerized Polypyrrole on Highly Oriented Pyrolytic Graphite Electrode, Electroanalysis. 15 (2003) 115-120.

[27] G. Appela, D. Schmeißera, J. Bauer, M. Bauer, H.J. Egelhaaf, D. Oelkrug, The formation of oligomers in the electrolyte upon polymerization of pyrrole. Synthetic Met. 99 (1999) 69-77.

[28] M. Grzeszczuk, J. Kalenik, A. Kępas-Suwara, Phase boundaries in layer-by-layer electrodeposited polypyrrole resulted from 2D-3D growths of polymer sublayers, J. Electroanal. Chem. 626 (2009) 47-58.

[29] T. Licona-Sánchez, G. Álvarez-Romero, L. Mendoza-Huizar, C. Galán-Vidal, M. Palomar-Pardavé, M. Romero-Romo, H. Herrera-Hernández, J. Uruchurtu and J. JuárezGarcía, Nucleation and Growth Kinetics of Electrodeposited Sulfate-Doped Polypyrrole: Determination of the Diffusion Coefficient of SO42- in the Polymeric Membrane, J. Phys. Chem. B 114 (2010), 9737-9743.

[30] G. Longo, G. Pompeo, J. S. Moreno, S. Panero, M. Girasole, F. Ronci, A. Cricenti, Morphological characterization of innovative electroconductive polymers in early stages of growth, Surf. Coat. Technol. 207 (2012) 286-292.

[31] D. Cossement, F. Plumier, J. Delhalle, L. Hevesi, Z. Mekhalif, Electrochemical deposition of polypyrrole films on organosilane-modified ITO substrates, Synth. Met. 138 (2003) 529-536. 
[32] M. F. Suárez, R. G. Compton, In situ atomic force microscopy study of polypyrrole synthesis and the volume changes induced by oxidation and reduction of the polymer, J. Electroanal. Chem. 462 (1999) 211-221.

[33] W. Chen, L. Chang-Ming, L. Yu, Z. Lu, Q. Zhou, In situ AFM study of electrochemical synthesis of polypyrrole/Au nanocomposite. Electrochem. Commun. 10 (2008) 1340-1343.

[34] R. Sharma, S. Lamba, S. Annapoorni, Magnetic properties of polypyrrole-coated iron oxide nanoparticles, J. Phys. D: Appl. Phys. 38 (2005) 3354-3359.

[35] T. K. Vishnuvardhan, V. R. Kulkarni, C. Basavaraja, S. C. Raghavendra, Synthesis, characterization and a.c. conductivity of polypyrrole/ $\mathrm{Y}_{2} \mathrm{O}_{3}$ composites, B. Mater. Sci. 29 (2006) 77-83.

[36] S. Yalcınkaya, C. Demetgül, M. Timur, N. Colak, Electrochemical synthesis and characterization of polypyrrole/chitosan composite on platinum electrode: Its electrochemical and thermal behaviors, Carbohyd. Polym. 79 (2010) 908-913.

[37] I.L. Lehr, S.B. Saidman, Corrosion protection of iron by polypyrrole coatings electrosynthesised from a surfactant solution, Corros. Sci. 49 (2007) 2210-2225.

[38] R. A. Campbell, R. W. Parker, P. R. Day, C. D. Bain, External Reflection FTIR Spectroscopy of the Cationic Surfactant Hexadecyltrimethylammonium Bromide (CTAB) on an Overflowing Cylinder, Langmuir 20 (2004) 8740-8753.

[39] C. Ling-Jian, M. Wang, Y. Hu, Q. Dong-Jin, M. Chen, Synthesis and mechanistic study of stable water-soluble noble metal nanostructures, Nanotechnology. 22 (2011) 285601 (10pp).

[40] J. Chen, M. Liu, H. Liu, L. Ma, C. Gao, S. Zhu, S. Zhang, Synthesis and properties of thermo- and $\mathrm{pH}$-sensitive poly(diallyldimethylammonium chloride)/poly(N,Ndiethylacrylamide) semi-IPN hydrogel, Chem. Eng. J. 159 (2010) 247-256. 
Table 1. Additives used in this study during electrodeposition, the corresponding integrated charge during PPy film deposition at $800 \mathrm{mV}$ (vs $\mathrm{Ag} / \mathrm{AgCl}$ ) on ITO coated PET electrode after at $300 \mathrm{~s}$, thickness of the resulting film and PPy oxidation potential obtained from cyclic voltammetry experiments in a potential range from $-300 \mathrm{mV}$ to $800 \mathrm{mV}$ at a scan rate of $50 \mathrm{mVs}^{-1}$.

Figure 1. Chronoamperometric curves of PPy deposition at $800 \mathrm{mV}$ (vs $\mathrm{Ag} / \mathrm{AgCl}$ ) on ITO coated PET electrode $(0.2 \mathrm{M}$ Py / $0.2 \mathrm{M} \mathrm{HCl} / 1 \mathrm{wt} \%$ additive) during $300 \mathrm{~s}$ showing the effect of several additives.

Figure 2. AFM images of PPy film deposited after 1.5 seconds at $800 \mathrm{mV}$ (vs $\mathrm{Ag} / \mathrm{AgCl}$ ) on ITO coated PET electrode. a) topography image, b) phase image.

Figure 3. Dimensionless plot of current maximum in chronoamperometric curves of Figure 1 of PPy compared with theoretical curves for a) 2D instantaneous and progressive nucleation, b) 3D instantaneous and progressive nucleation, and, for PPy-AOT compared with theoretical curves for c) 2D instantaneous and progressive nucleation and d) 3D instantaneous and progressive nucleation.

Figure 4. AFM images of PPy film deposited after 1.5 seconds at $800 \mathrm{mV}$ (vs $\mathrm{Ag} / \mathrm{AgCl}$ ) on ITO coated PET electrode in presence of CTAB, a) topography image, b) phase image, and in presence of AOT, c) topography image, d) phase image. 
Figure 5. AFM images of PPy film deposited after 1.5 seconds at $800 \mathrm{mV}$ (vs $\mathrm{Ag} / \mathrm{AgCl})$ on ITO coated PET electrode in presence of PDADMAC, a) topography image, b) phase image; and in presence of PSSMA, c) topography image, d) phase image.

Figure 6. Bode impedance plot of ITO electrodes before (filled circles) and after film deposition (hollow circles) of the PPy (in black) and of PPy in presence of AOT (in red), at $800 \mathrm{mV}$ (vs $\mathrm{Ag} / \mathrm{AgCl})$ during 1.5 seconds.

Figure 7. SEM images of the PPy films deposited after $300 \mathrm{~s}$ at $800 \mathrm{mV}$ (vs $\mathrm{Ag} / \mathrm{AgCl})$ on ITO coated PET electrode. (a, b) Low and high magnification of the PPy film deposited without additives, c) PPy film deposited in presence of CTAB, d) PPy film deposited in presence of AOT, e) PPy film deposited in presence of PDADMAC and f) PPy film deposited in presence of PSSMA.

Figure 8. FTIR spectra of PPy deposited after $300 \mathrm{~s}$ at $800 \mathrm{mV}$ (vs $\mathrm{Ag} / \mathrm{AgCl}$ ) on ITO coated PET electrode. a) PPy film deposited in presence of AOT, b) PPy film deposited in presence of CTAB, c) PPy film deposited in presence of PDADMAC, d) PPy film deposited in presence of PSSMA and e) PPy deposited without additives.

Figure 9. Adsorption mechanisms of non-electro active additives on PPy films. a) Entanglement, for polymeric additives, b) adsorption, for surfactant additives, c) SEM image of PPy film deposited in presence of polymeric additive, PSSMA and d) SEM image of PPy film deposited in presence of surfactant additive, AOT. 
Figure 10. Adhesion test performed on the PPy films deposited after $300 \mathrm{~s}$ at $800 \mathrm{mV}$ (vs $\mathrm{Ag} / \mathrm{AgCl}$ ) on ITO coated PET electrode. a) PPy film deposited without additives, b) PPy film deposited in presence of CTAB, c) PPy film deposited in presence of AOT. d) PPy film deposited in presence of PDADMAC, e) PPy film deposited in presence of PSMMA 


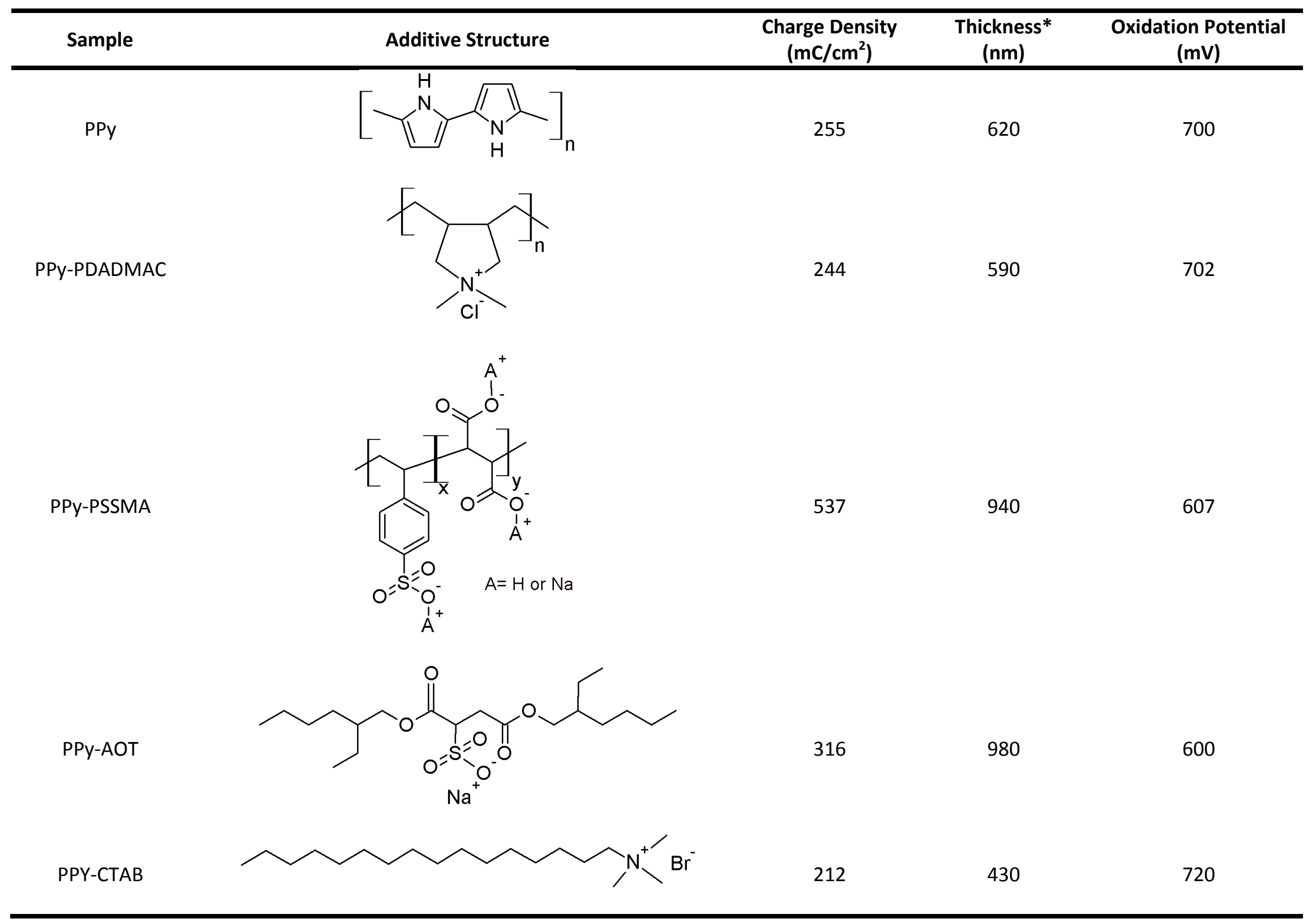

* The film thickness was measured from the SEM images. 


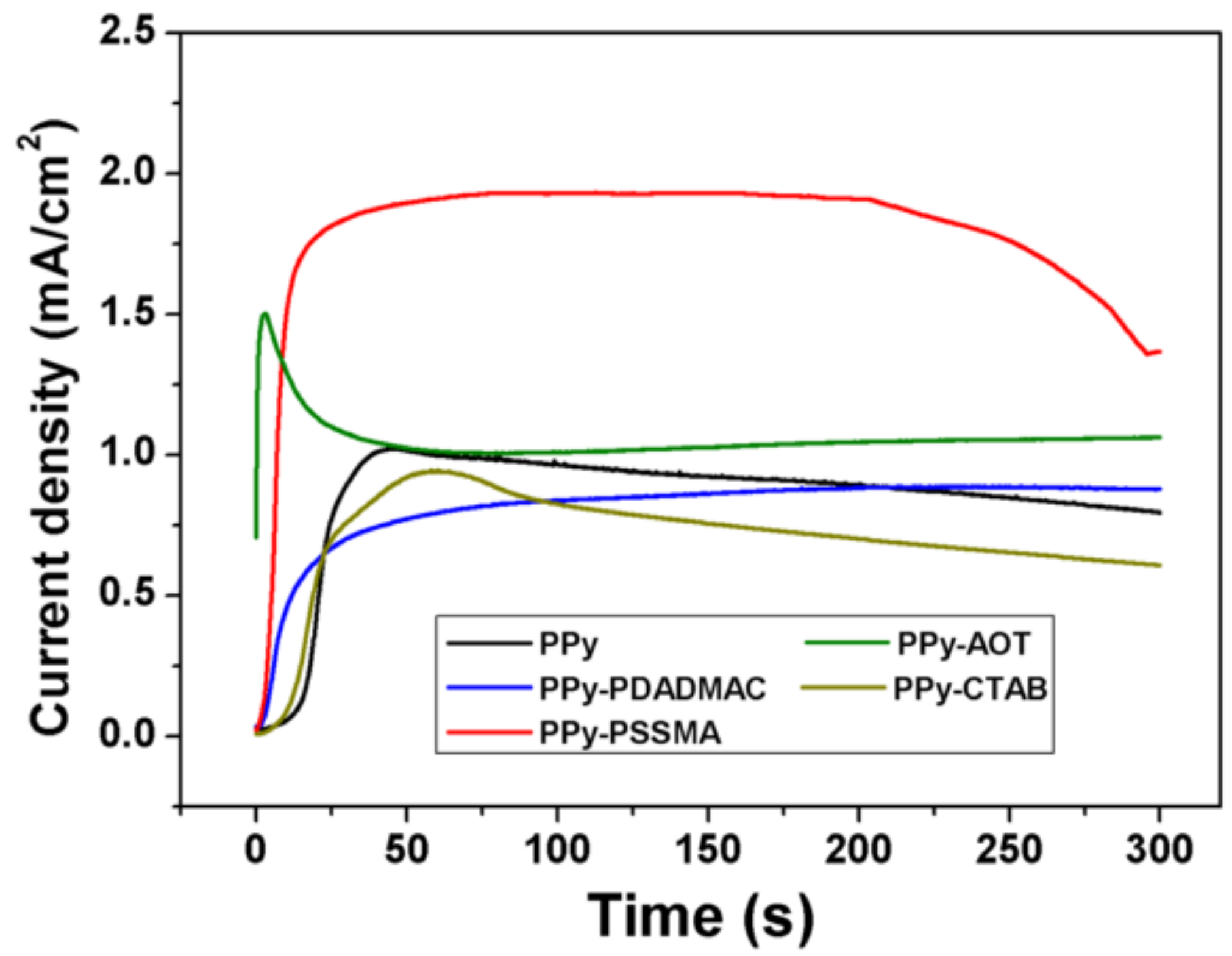



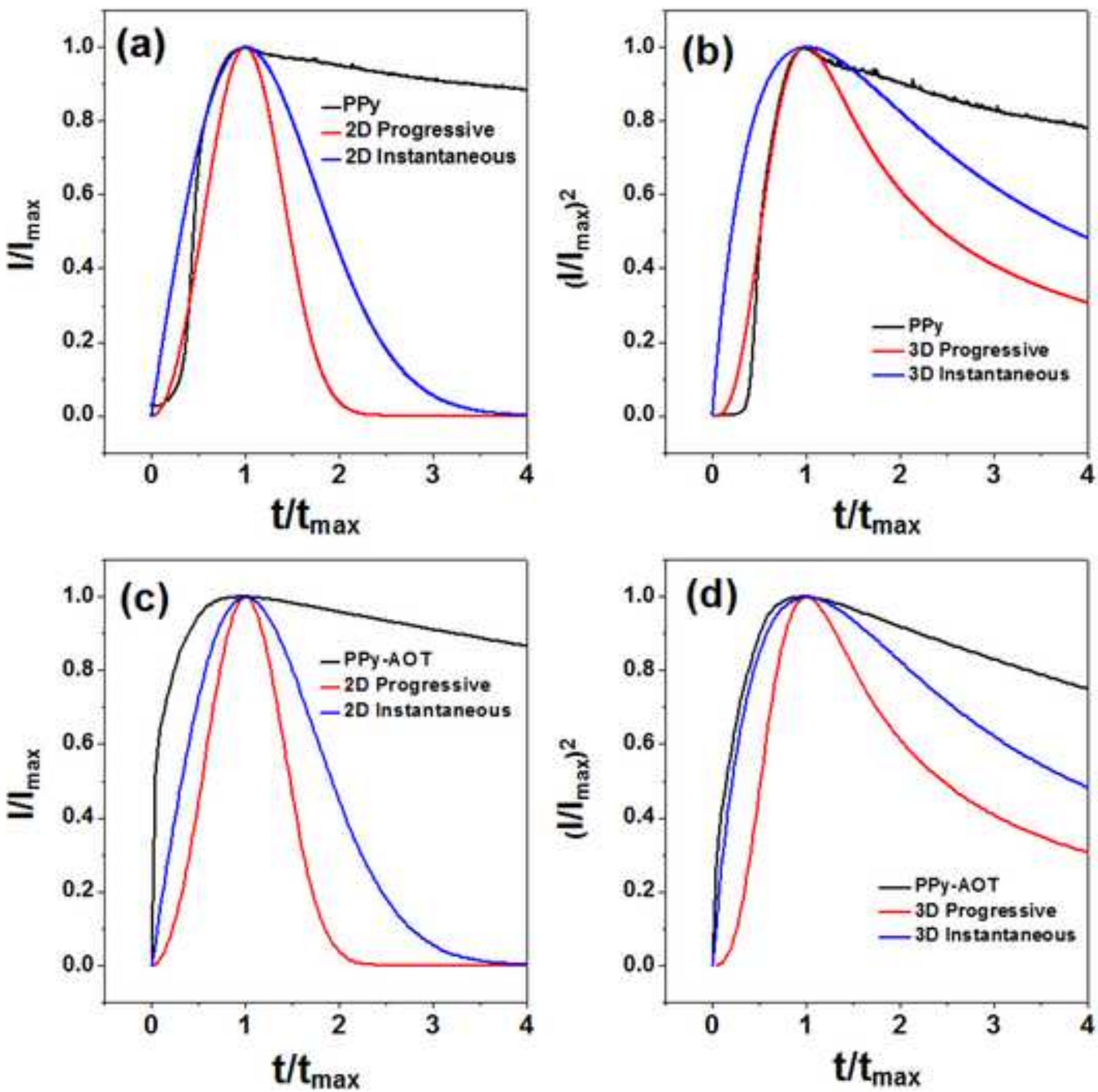

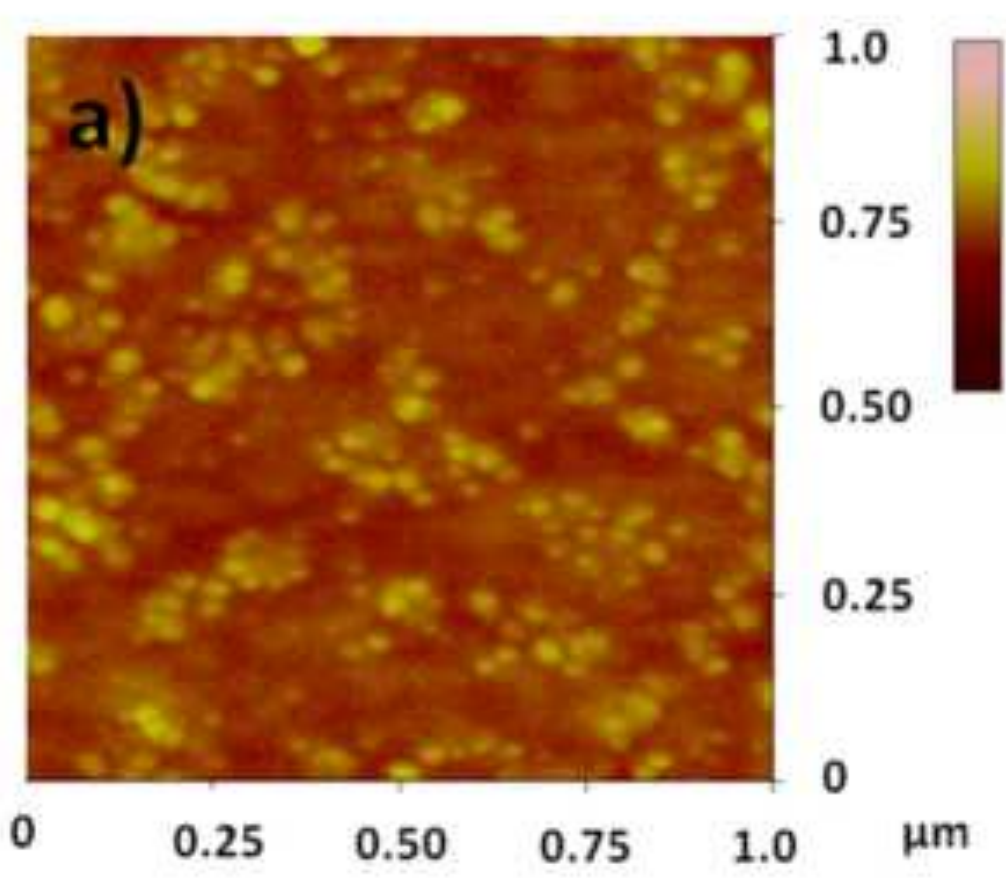

$100 \mathrm{~nm}$

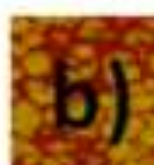

1.0 $300^{\circ}$

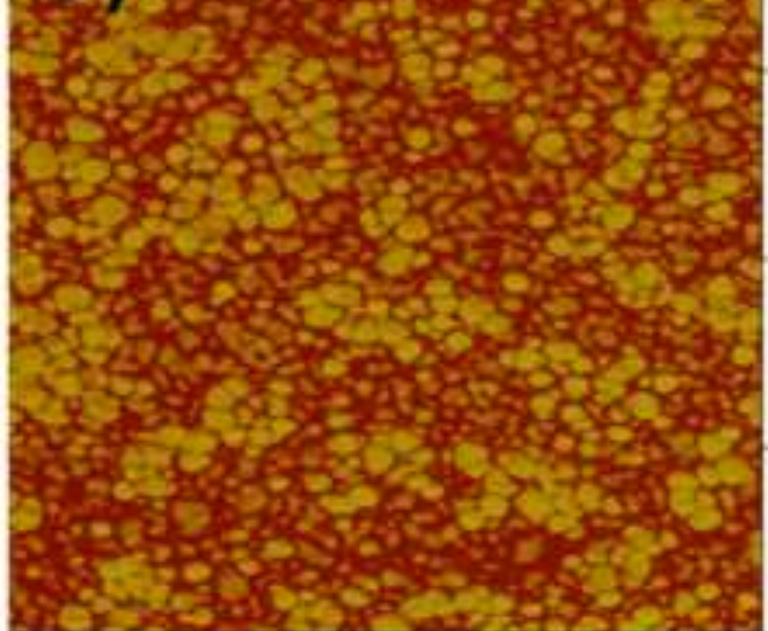

0.75

$0 \mathrm{~nm}$

\subsection{5 \\ $0.50 \square 0^{\circ}$}

0.25

0

0.25

0.50

0.75

1.0

0

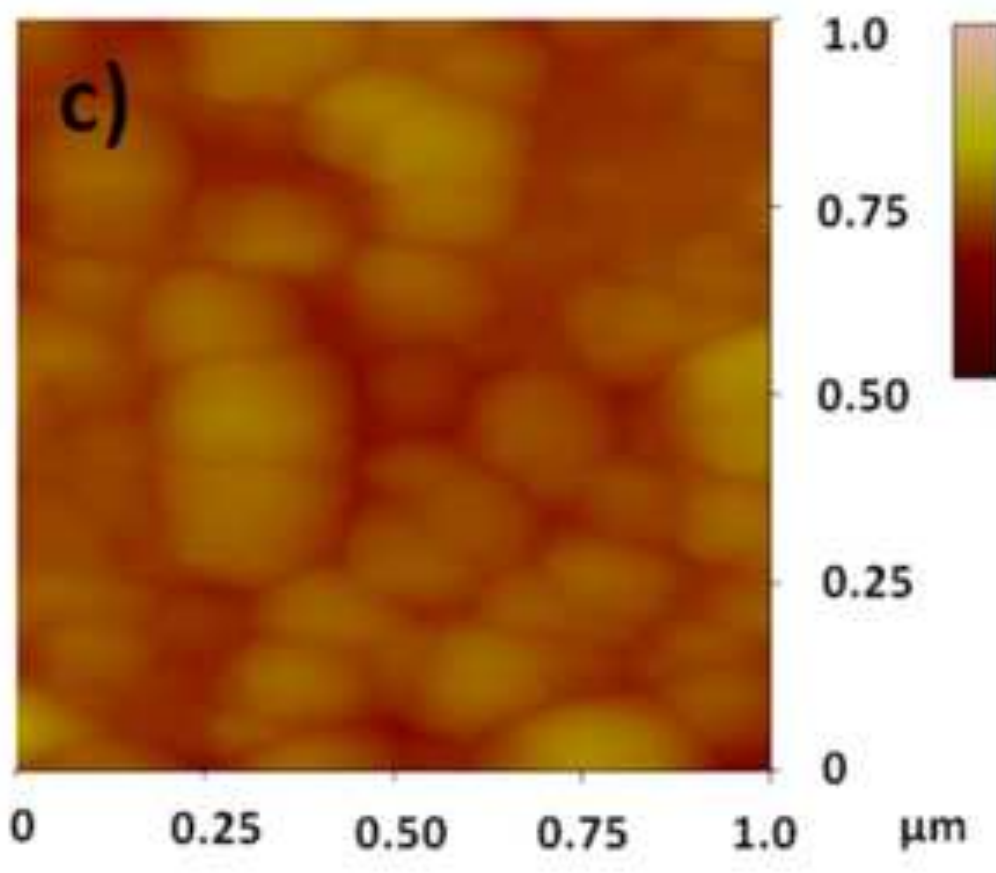

$516 \mathrm{~nm}$

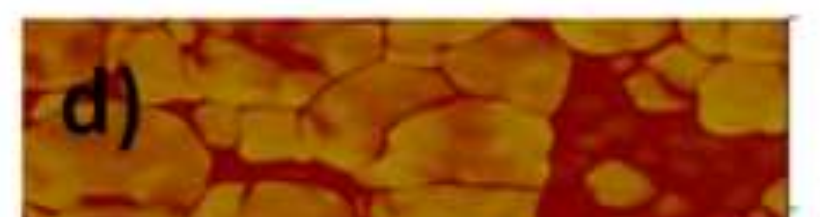

$1.0 \square 180^{\circ}$

$258 \mathrm{~nm}$

$0 \mathrm{~nm}$

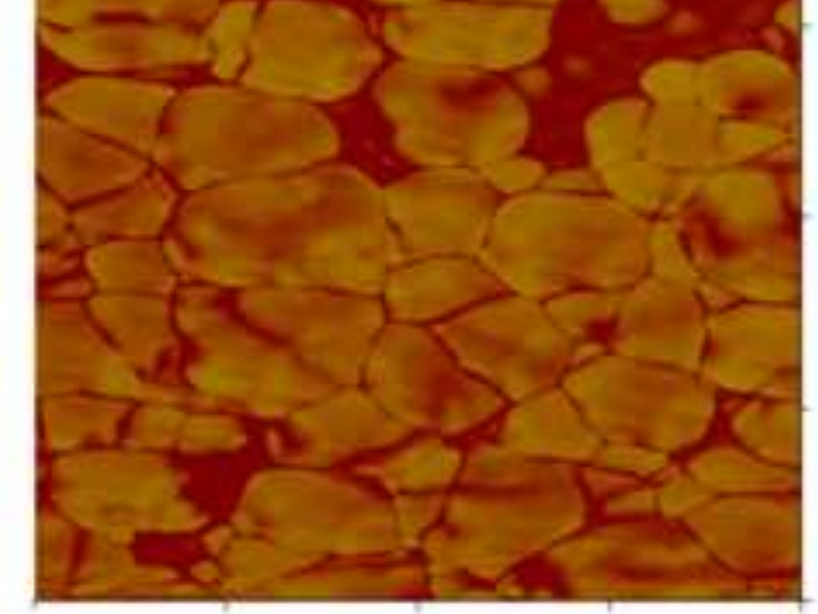

0.75

$90^{\circ}$

0.50

0.25

0

0.25

0.50

0.75

1.0

$\mu \mathrm{m}$ 

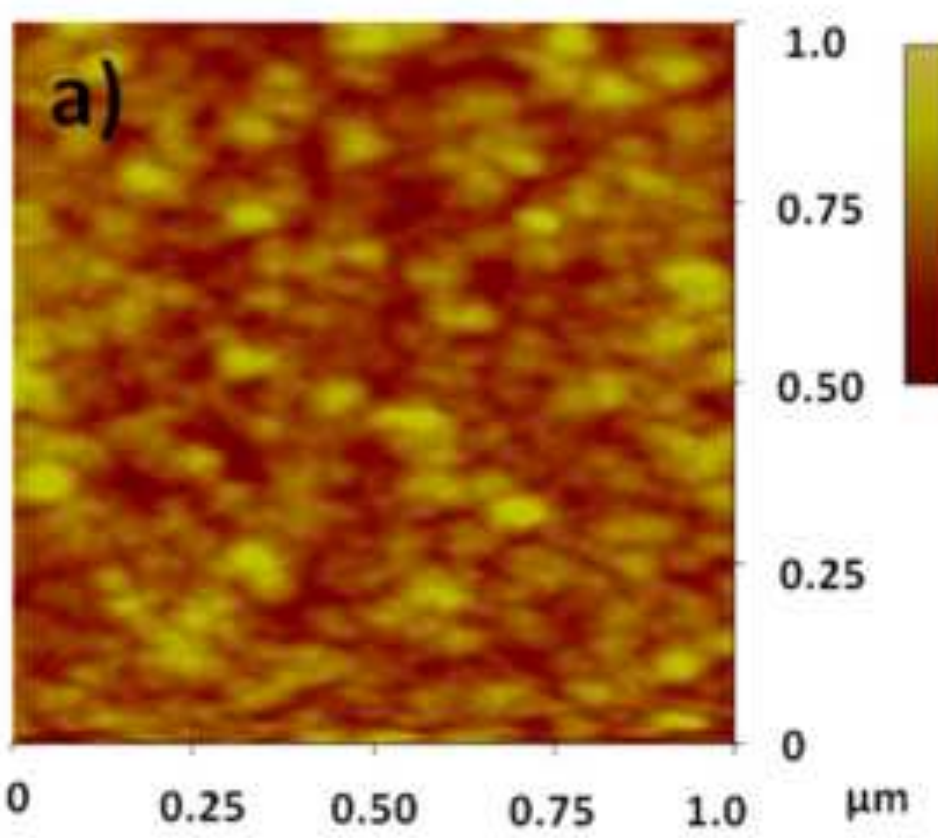

$$
\begin{aligned}
& 0 \\
& 0
\end{aligned}
$$
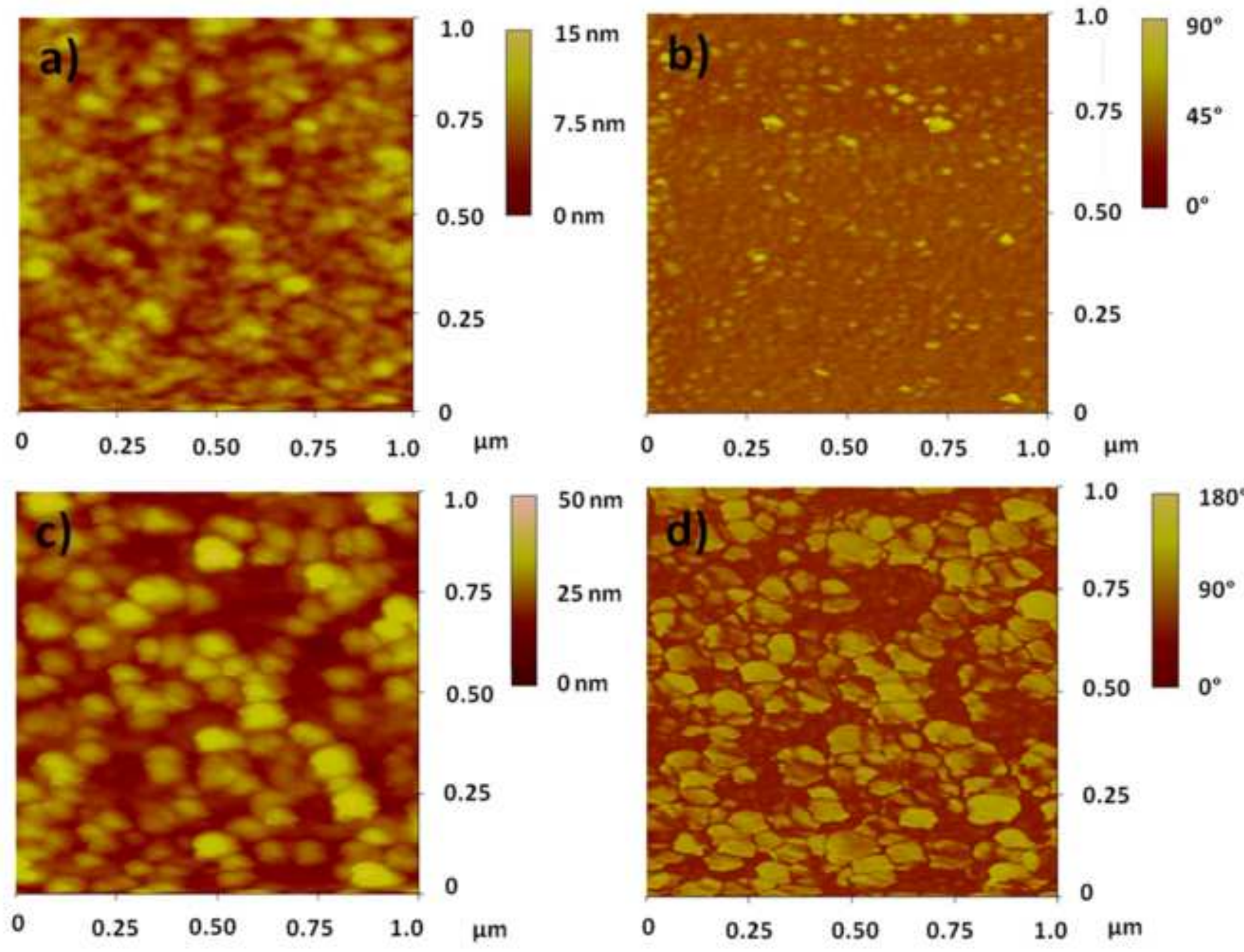


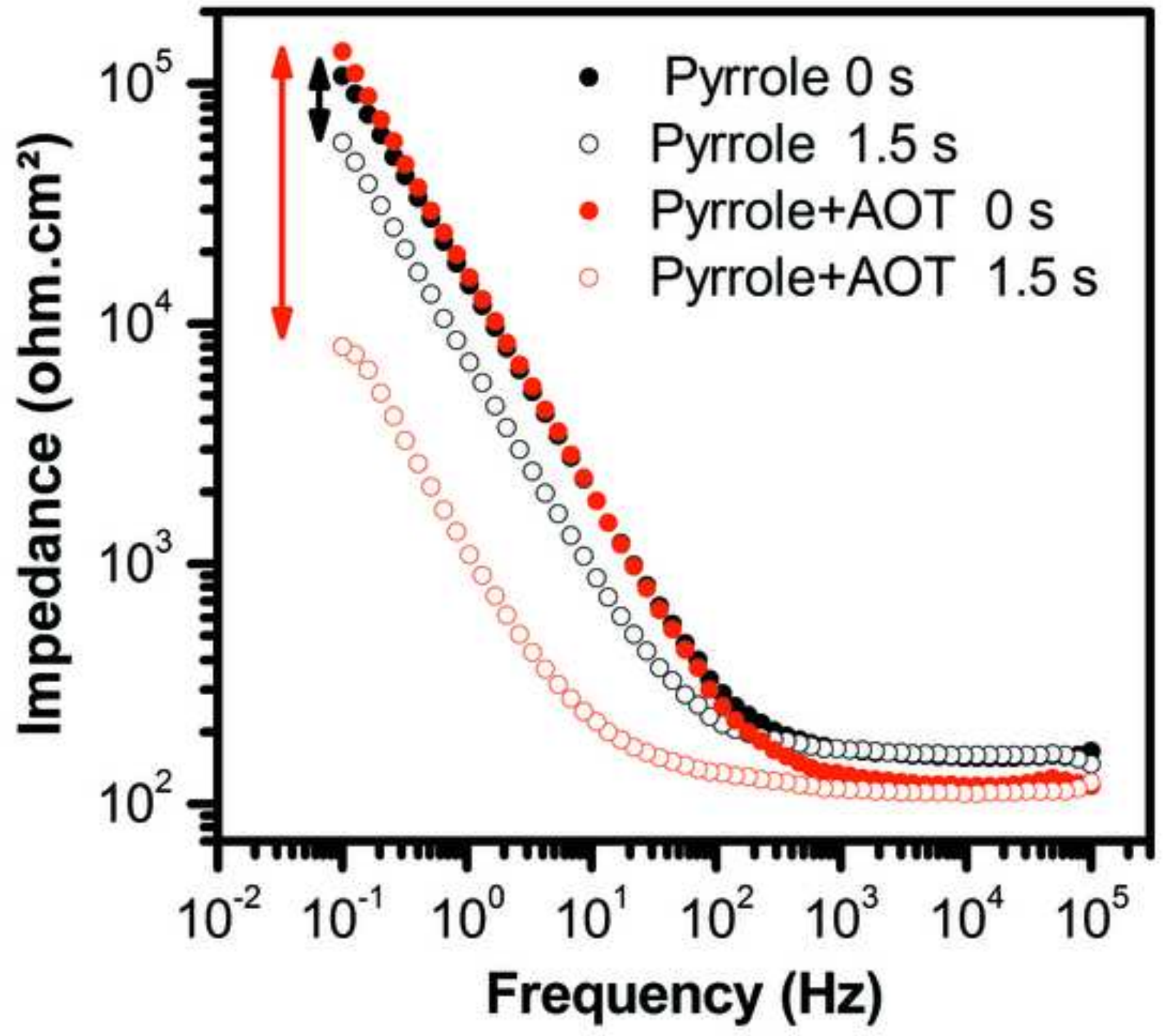



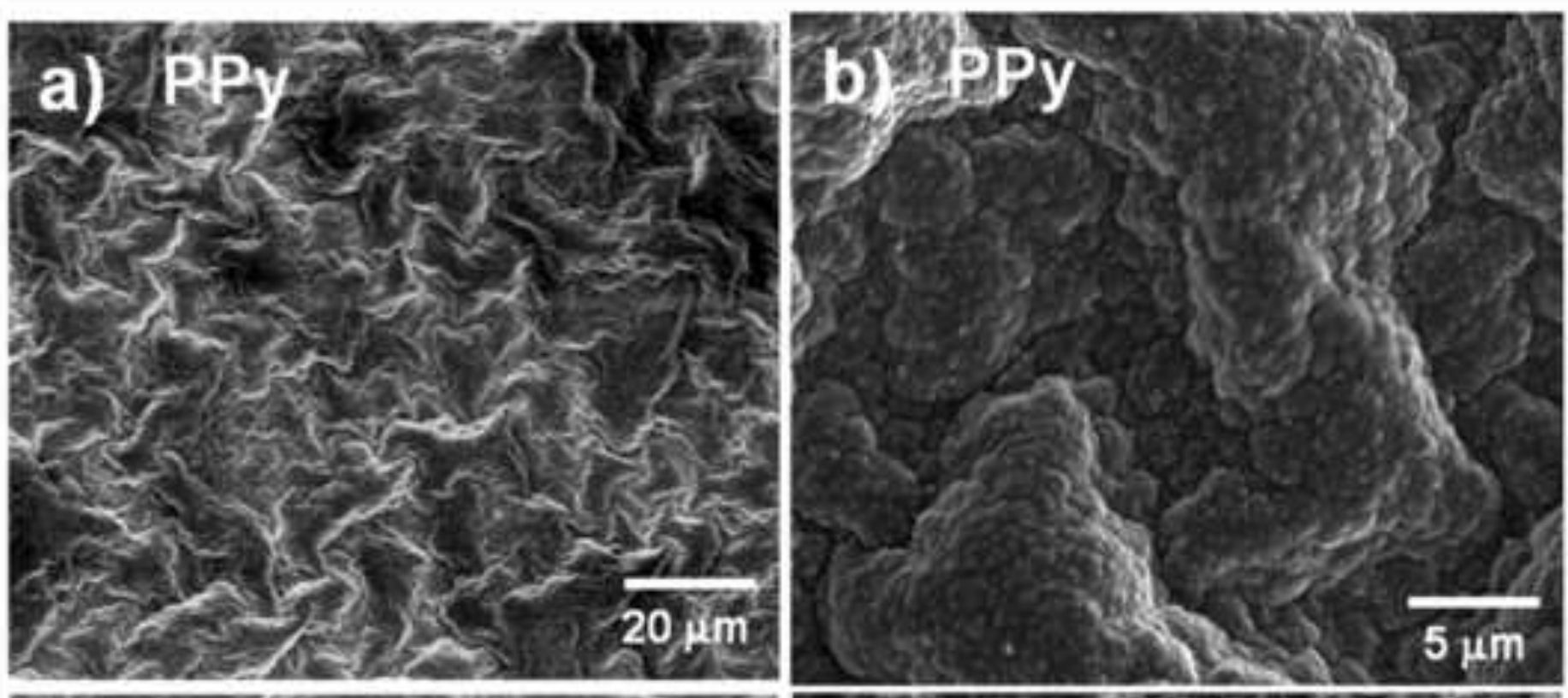

\section{c) PPy-CTAB}

d) PPY-AOT

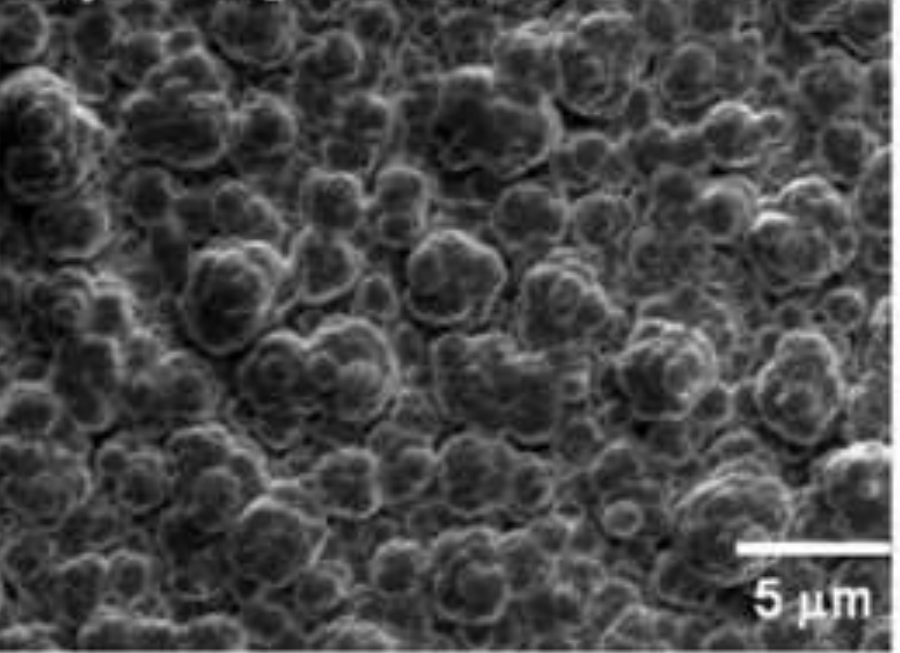

e) PPy-PDADMAC

f) PPy-PSSMA

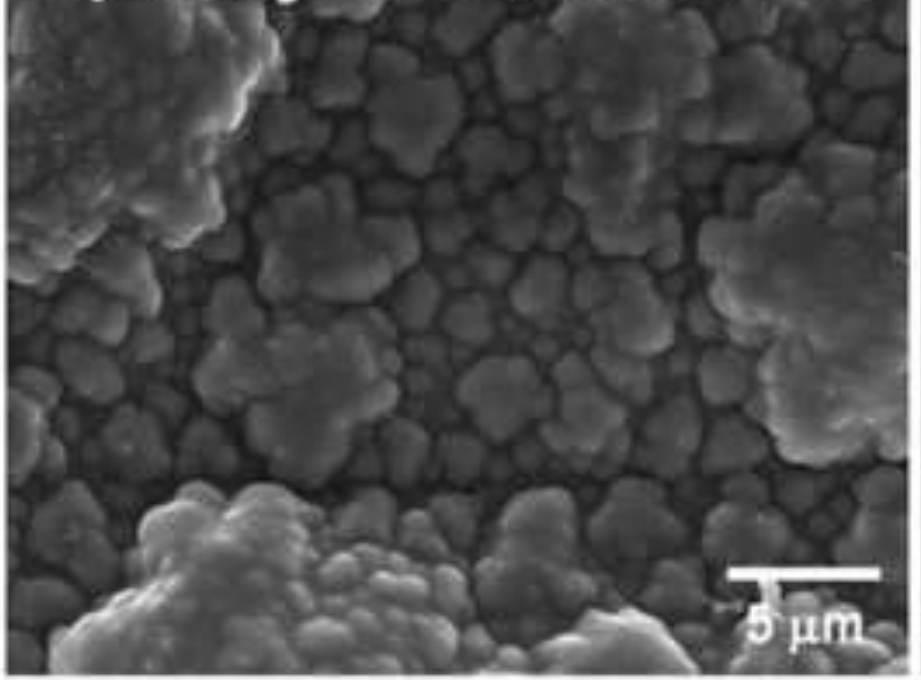




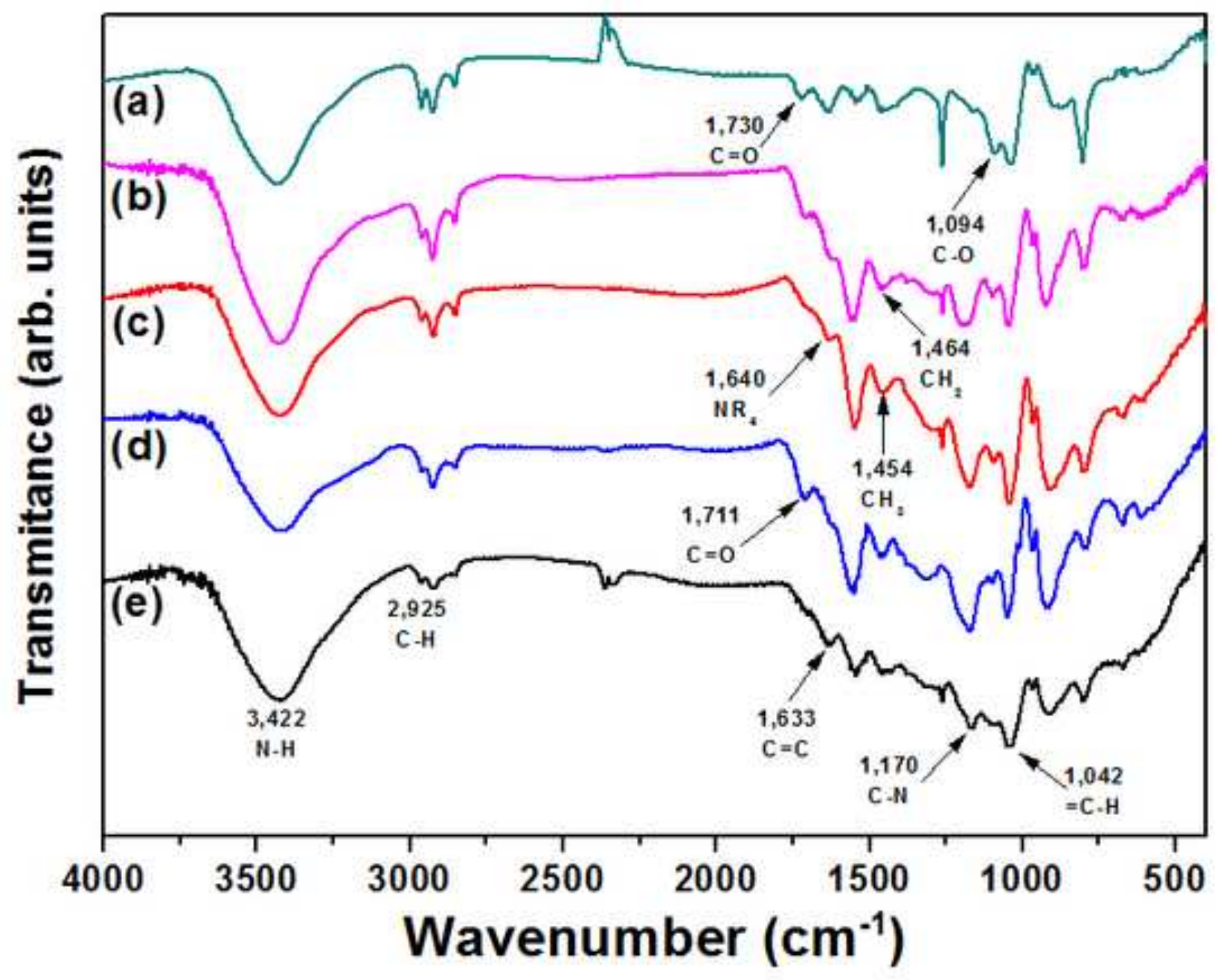


a) Entanglement

b) Adsorption

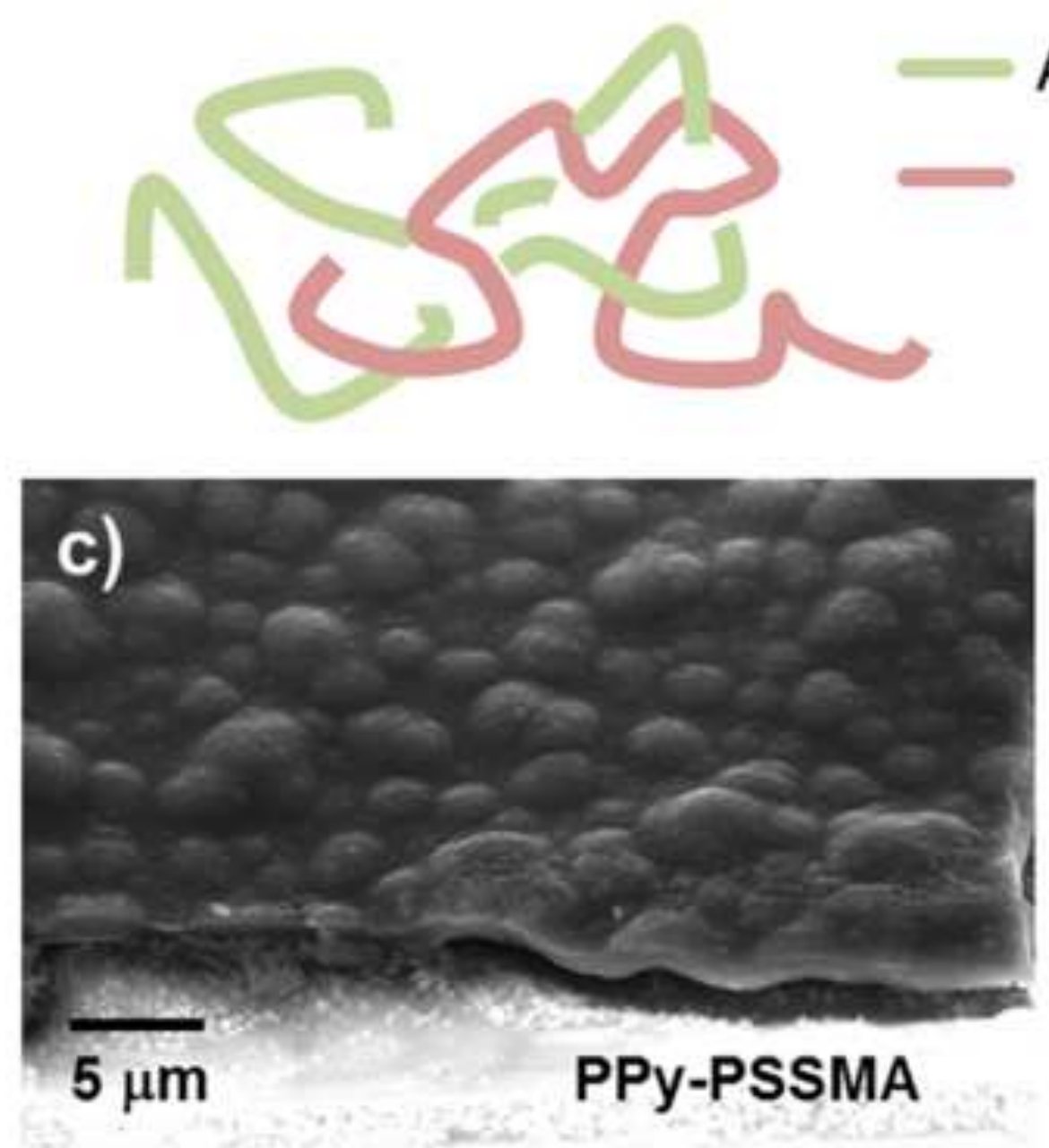

Additive

PPy
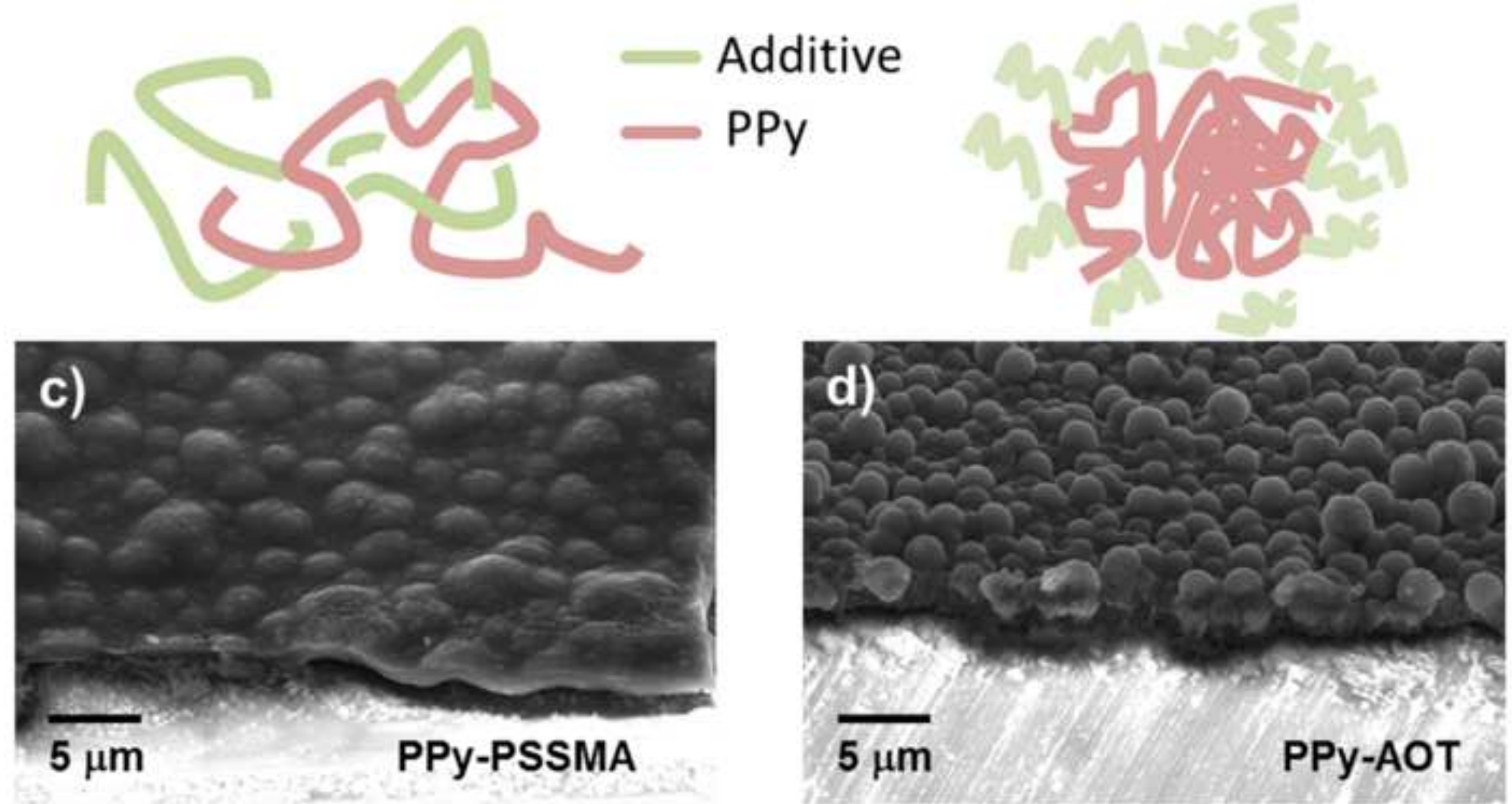

\section{Additive}

. 


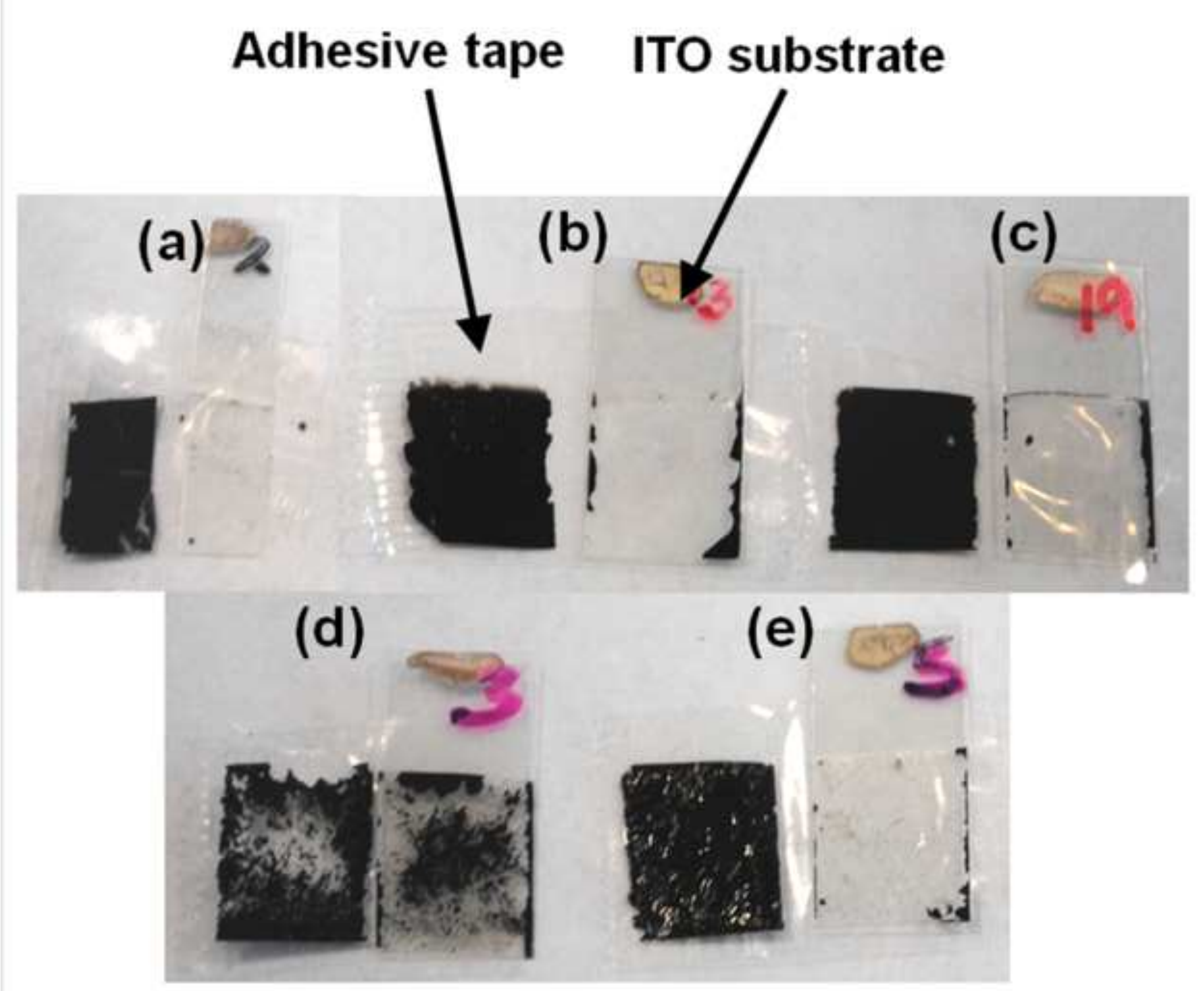

